\title{
A Meta-analysis of immune signaling pathways between human type 2 diabetic tissue and mouse bone repair
}

\author{
James McCauley, Ashley Walsh, Justin F Bejar, Jason Ianni, Mannesah Georges, Zaneta Zachwieja, Robert Gray, Tinchun Chu, Jessica \\ Cottrell and Sulie L Chang* \\ Seton Hall University, 400 South Orange Avenue, South Orange, NJ, USA
}

\begin{abstract}
Type II diabetes mellitus (T2DM) is a chronic metabolic disorder characterized by insulin insensitivity, hyperglycemia, and immune dysregulation. Recent findings have shown that T2DM has a significant impact on the skeletal system, including the impairment of the fracture healing process which commonly leads to nonunion. Throughout the process, heterotypic interactions between different immune cells are required for the recruitment and differentiation of osteogenic cells vital for fracture repair. The purpose of this study was to compare inflammatory gene expression induced in T2DM with those occurring during fracture repair with a specific focus on immune cell expression. Using publicly available RNA-seq datasets and Ingenuity Pathway Analysis (IPA), we compared gene expression profiles of human diabetic and non-diabetic data to gene expression profiles of mice post-fracture. IPA core analysis of diabetic vs. non-diabetic immune gene expression revealed top canonical pathways ( $\mathrm{p}$-value $<1.0 \times 10^{-6}$ ) involved in the Th1 Activation Pathway, Granulocyte Adhesion and diapedesis, and IL-7 Signaling, had an average activation $\mathrm{z}$-score of -2.373 , thus exhibiting a predicted inhibition when compared to non-diabetic controls. Additionally, top upstream inflammatory regulators such as TNF- $\alpha, \mathrm{IL}-1 \mathrm{~B}$, and IL-6 also exhibited an average $3.5 \mathrm{log}$-fold reduction in expression. When examining gene expression in normal fracture repair, previous upstream inflammatory regulators exhibit an average $2.1 \mathrm{log}$-fold increase. Our results suggest that during fracture repair, the early immune response required for recruitment of osteogenic cells and repair is impaired in T2DM signaling.
\end{abstract}

\begin{abstract}
Abbreviations: T2DM: Type 2 Diabetes Mellitus; MSCs: Mesenchymal Stem Cells.
\end{abstract}

\section{Introduction}

In type 2 diabetes mellitus (T2DM), the glucose homeostatic function of insulin is impaired which leads to negative physiological changes [1,2] like failed bone healing. In the U.S. annually, 790,000 diabetic fractures do not heal properly $[3,4]$, each costing $\$ 30,000$ more in patient care [5]. Unfortunately, the connection between the immune system, T2DM, and fracture repair is still unclear. After fracture, the acute inflammatory response recruits' cells to support hematoma formation, callus formation, and osteogenesis [6,7]. Recruited mesenchymal stem cells (MSCs) can differentiate into osteogenic cells required for the generation of the callus [8]. This stabilizes the fracture and acts as a scaffold for deposition of mature lamellar bone [9]. In diabetics, this process takes significantly longer. Hamon et al. observed that diabetic rats have increased rates of non-union and lower bone mineral density at 12 weeks post-fracture when compared to nondiabetics [10]. Roy et al. [11] correlated these changes with declines in transcription factors such as Dlx5 are inhibited under hyperglycemic conditions and required for osteogenic differentiation. This inhibition is thought to reduce MSC commitment, which depletes the available osteoprogenitor cells necessary for fracture repair. Recent studies have shown that immune cells such as macrophages are also critical for fracture repair. Mouse macrophage ablation studies in fracture models show a significant impairment in the fracture healing process $[12,13]$. These myeloid derived immune cells secrete mediators which regulate processes like matrix synthesis and osteogenesis [14]. Similar immune components are known to be dysregulated in TD2M $[15,16]$. Therefore, in this study we use Ingenuity Pathway Analysis to compare human T2DM gene expression profiles with those of mice post-fracture to determine connections between immune dysregulation, T2DM, and fracture repair.

\section{Methods}

\section{Literature search utilizing ingenuity pathway analysis}

The Ingenuity Pathway Analysis (IPA, Qiagen, The Netherlands) Knowledge Base was utilized to locate articles with RNA-seq and gene expression data related to diabetes, fracture repair, and myeloid cell activity. IPA's BioProfiler function was used to search for specific gene functions and molecule activity while excluding drug and chemical markers. The literature search yielded only two studies, "Diabetic complications and dysregulated innate immunity" [17] and "Transcriptomic signatures reveal immune dysregulation in human diabetic and idiopathic gastroparesis" [18] that contained RNA-seq data that overlapped with our search criteria and were used for subsequent meta-analysis and core analysis.

Comparison of gene expression in T2DM, non-diabetic, and acute fracture repair

First, the data were extrapolated and used to analyze transcriptome patterns of human T2DM to non-diabetic and mouse non-diabetic

${ }^{\star}$ Correspondence to: Sulie L. Chang, Seton Hall University, 400 South Orange Avenue, South Orange, NJ, USA, Tel: 973-761-9456; E-mail: sulie.chang@shu.edu

Key words: inflammation, type 2 diabetes, fracture, myeloid, ingenuity pathway analysis

Received: February 05, 2020; Accepted: February 23, 2020; Published: February 26, 2020 
unfractured to mouse non-diabetic post-fracture with a specific focus on immune cell related gene expression and function. In Grover et al.'s study, gene expression data from smooth muscle was compared between T2DM patients vs. non-diabetics controls [17]. Data were uploaded to IPA in Excel files and annotated prior to core analysis using IPA's flexible file format. For data obtained from Grover et al. [17] 564 genes were inputted for analysis with 549 gene IDs successfully mapped and 15 gene IDs remaining unmapped and no additional cutoffs to fold-change in expression and p-values were assigned.

In Bais et al.'s [18] study, gene expression data was extracted at day 3 post-fracture, which is established as part of the acute inflammatory phase of fracture repair in mice. For Bais et al. [18] 16,505 genes were inputted for analysis with 13,454 gene IDs successfully mapped 3051 gene IDs remaining unmapped. For this data set, cutoff values of -1.5 and +1.5 were implemented for fold change in expression to reduce the analysis of genes inputted to 1998 genes. Since both T2DM and fracture transcriptome represent sustained inflammatory events, these two datasets were compared to each other to find links between immune dysregulation, T2DM, and fracture repair that span both the mouse and human systems.

\section{Data IPA analysis}

Predictions of the activation states of pathways and regulators was conducted through IPA's z-scoring system. These z-scores act as a prediction model in which IPA can accurately state if a specific pathway or molecule will be activated or inhibited based on gene expression datasets uploaded to its core expression analysis feature. IPA can then compare the expression patterns between these uploaded datasets and the existing datasets in the IPA Knowledge Base. Any inconsistencies between the uploaded datasets and the IPA Knowledge Base will subtract from the overall z-score while consistencies add to the z-score. A negative $\mathrm{z}$-score is indicative of a predicted state of inhibition while a positive $z$-score represents a predicted state of activation. When analyzing canonical pathways, the top 20 results (consisting of the lowest 20 p-values) were selected for each category. For upstream

regulators, the top 15 results (consisting of the lowest $15 \mathrm{p}$-values) were selected.

\section{Results}

\section{Canonical signaling pathways involved in T2DM dysregulation of the immune response}

When the uploaded dataset from Grover et al. was uploaded to the IPA, IPA predicted the top 20 canonical pathways, based on lowest p-values, to be inhibited overall (Figure 1, blue- shaded bars). Immune and inflammatory signaling pathways such as the Th1 pathway, IL-7 pathway, and Granulocyte Adhesion and Diapedesis functions all exhibited an average negative z-score of -2.737 (Figure 1, Table 1).

\section{Expression of Pro-inflammatory Mediators IL1- $\beta$ and TNF- $\alpha$ are Significantly Inhibited in T2DM}

In addition to top canonical pathways, IPA also predicted the activation states of similar upstream regulators using the same z-scoring system. In the T2DM dataset, inflammatory molecules TNF- $\alpha$, IL$1 \beta$, and IL- 6 were predicted to be inhibited with an average negative z-score of -5.952 (Table 1). Aside from cytokines, other endogenous inflammatory molecules such as prostaglandin E2 and leukotriene D4 were predicted to be inhibited with $\mathrm{z}$-scores of -3.175 and -5.281 , respectively (Table 2).

Table 1. Z-scores and P-values of Top 7 Downregulated Canonical Pathways in T2DM

\begin{tabular}{|l|c|c|}
\hline Pathway & Z-score value & p-value \\
\hline TH2 Pathway & -2.11 & $2.22 \mathrm{E}-10$ \\
\hline Granulocyte Adhesion and Diapedesis & -2.113 & $8.46 \mathrm{E}-09$ \\
\hline STAT3 & -1.414 & $1.31 \mathrm{E}-08$ \\
\hline TH1 Pathway & -2.887 & $1.46 \mathrm{E}-07$ \\
\hline Osteoathritis Pathway & -1 & $3.87 \mathrm{E}-07$ \\
\hline iCOS-iCOSL Signaling T Helper Cells & -2.714 & $1.79 \mathrm{E}-06$ \\
\hline IL-7 Signaling Pathway & -2.121 & $3.16 \mathrm{E}-06$ \\
\hline
\end{tabular}

Analysis: Diabetic Gastroparesis vs non-diabetic controls analysis $2 \cdot 2019 \cdot 03 \cdot 05$ 01:42 PM

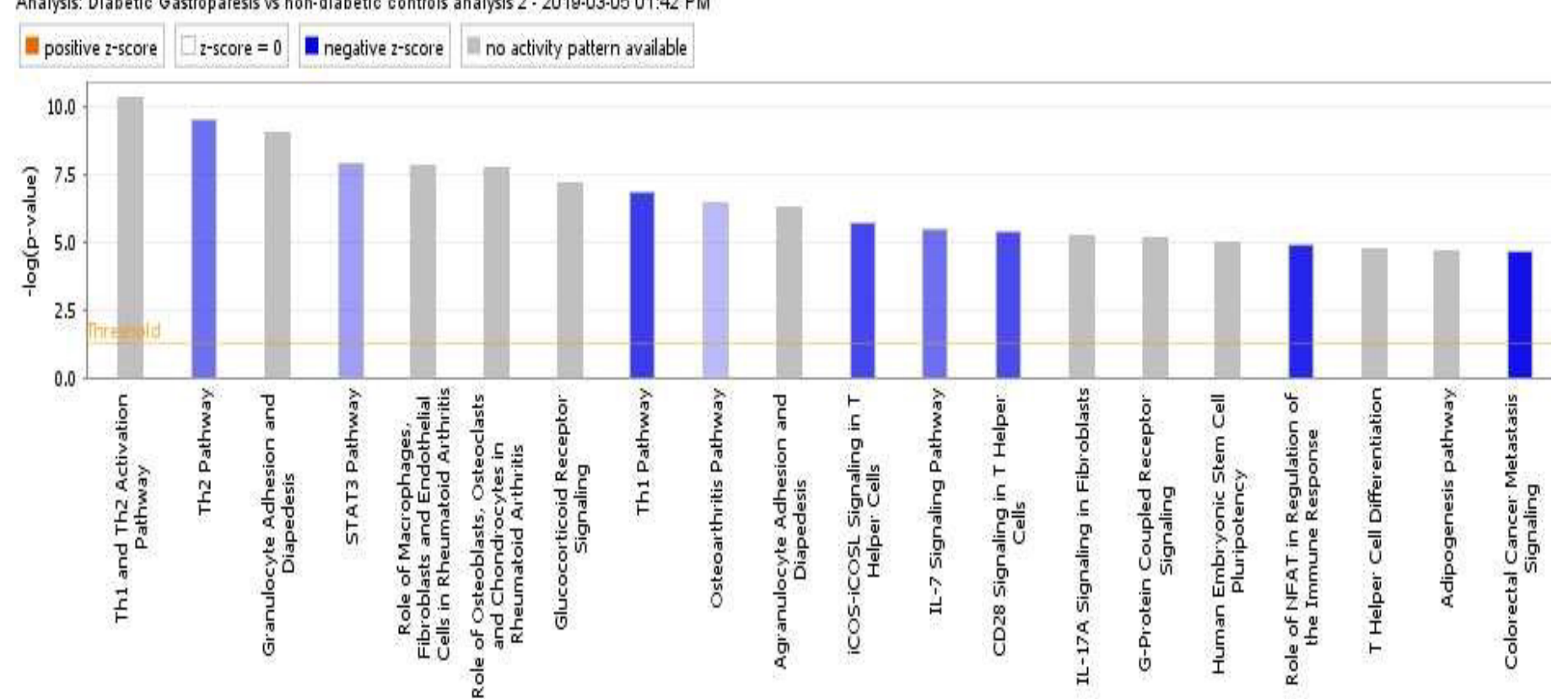

Figure 1. Canonical signaling pathways involved in T2DM dysregulation of the immune response 
Table 2. Predicted activation states of inflammatory genes in type 2 diabetics

\begin{tabular}{|c|c|c|c|c|}
\hline Upstream Regulator & Molecule Type & Predicted Activation State & Activation z-score & p-value of overlap \\
\hline TNF & Cytokine & Inhibited & -6.036 & $9.84 \mathrm{E}-61$ \\
\hline IL1 $\beta$ & cytokine & Inhibited & -6.451 & $2.83 \mathrm{E}-46$ \\
\hline beta-estradiol & chemical - endogenous & Inhibited & -4.474 & $2.8 \mathrm{E}-40$ \\
\hline PDGF BB & complex & Inhibited & -7.094 & $6.1 \mathrm{E}-40$ \\
\hline TGFB1 & growth factor & Inhibited & -4.843 & $1.29 \mathrm{E}-39$ \\
\hline prostaglandin E2 & chemical - endogenous & Inhibited & -3.175 & $5.51 \mathrm{E}-39$ \\
\hline IFNG & cytokine & Inhibited & -4.492 & $1.5 \mathrm{E}-34$ \\
\hline leukotriene D4 & chemical - endogenous & Inhibited & -5.281 & $1.66 \mathrm{E}-34$ \\
\hline GPER1 & G-protein coupled receptor & Inhibited & -5.202 & $1.05 \mathrm{E}-33$ \\
\hline $\mathrm{NR} 3 \mathrm{C} 1$ & nuclear receptor & Inhibited & -2.549 & $4.16 \mathrm{E}-33$ \\
\hline IL2 & cytokine & Inhibited & -4.739 & $1.52 \mathrm{E}-28$ \\
\hline IGF1 & growth factor & Inhibited & -4.599 & $1.56 \mathrm{E}-28$ \\
\hline CD40LG & cytokine & Inhibited & -4.404 & $2.23 \mathrm{E}-28$ \\
\hline HGF & growth factor & Inhibited & -4.95 & $2.44 \mathrm{E}-28$ \\
\hline IL6 & cytokine & Inhibited & -5.371 & $1.96 \mathrm{E}-25$ \\
\hline
\end{tabular}

Canonical signaling pathways involved in early fracture repair in non-diabetic conditions

Gene expression from early fracture repair in non-diabetic conditions were uploaded to IPA's core expression analysis feature. The top 20 canonical pathways from this expression dataset reveal varied states of pathway inhibition (blue shaded bars) and ac Pathway and the LPS/IL-1 Mediated Inhibition of RXR Function with an average z-score of 2.745 (Figure 2, Supplemental Table 3). Clear bars are indicative of a $\mathrm{z}$-score of 0 and thus have no difference in activity while gray shaded bars, such as Atherosclerosis signaling, indicate that no general prediction pattern was available from IPA's z-scoring system.

Expression of pro-inflammatory mediators IL1- $\beta$ and TNF- $\alpha$ is upregulated early during fracture repair in non-diabetic conditions

Gene expression data sets pertaining to fracture repair in non-diabetic conditions uploaded to IPA's core analysis predicted inflammatory molecules IL- $1 \alpha$, IL1- $\beta$, and TNF- $\alpha$ to be activated in early fracture repair with respective $\mathrm{z}$-scores of 3.311, 4.221, and 2.908 (Table 4). Additionally, genes related directly to the initiation and progression of fracture repair, BMP2 and RUNX2, were also predicted to be activated early during fracture repair in non-diabetic conditions (respective $\mathrm{z}$-scores of 3.484 and 2.391).

Inhibition of upstream inflammatory mediator TNF- $\alpha$ results in general suppression of downstream transcription factors involved in inflammation and enhancement of osteogenesis

IPA's mechanistic network feature for reduced TNF- $\alpha$ activity in T2DM reveals an overall suppression of downstream signaling targets (Figure 3). The signaling networks scores predicted activation states of downstream targets based on the z-scores of upstream regulators seen in table 1 . The downstream network shows that all downstream signaling are predicted to have suppressed or inhibited activity under hyperglycemic conditions. Some of these targets include transcription factors involved in inflammation (NF-k $\beta)$ and transcription factors implicated in the enhancement of osteogenesis (STAT3).

\section{Discussion and conclusion}

The immune response plays a significant role in the process of fracture repair and it is often dysregulated in T2DM. These inflammatory responses are driven by immune signaling pathways and the release
Table 3. Z-Scores and P-values for Top 7 regulated canonical pathways in non-diabetic fracture healing

\begin{tabular}{|l|c|c|}
\hline & Z-score value & p-value \\
\hline GP6 Signaling Pathway & 2.887 & $5.40 \mathrm{E}-05$ \\
\hline Osetoarthritis Pathway & 1.604 & $8.93 \mathrm{E}-05$ \\
\hline LPS/IL-1 Inhibiition of RXR Function & 3.783 & $1.65 \mathrm{E}-04$ \\
\hline Inhibition of Matrix Metalloproteases & -0.816 & $2.15 \mathrm{E}-04$ \\
\hline Apelin Liver Signaling Pathway & 2 & $2.25 \mathrm{E}-03$ \\
\hline Gas Signaling & 1.134 & $-2.84 \mathrm{E}-03$ \\
\hline Dermatan Sulfate Biosynthesis (Late Stage) & -1.342 & $-3.57 \mathrm{E}-03$ \\
\hline
\end{tabular}

of cytokines at the fracture site [19]. Our analysis shows a significant dysregulation and suppression of canonical immune signaling pathways in T2DM including the Th1, granulocyte adhesion and diapedesis, and TNF- $\alpha$ regulation which all play a significant role in host inflammatory responses (Figure 1 and 3). The Th1 response requires high levels of inflammation and causes a strong cell-mediated immune response [20]. The Th1 response is important to macrophage activation, which is essential to fracture repair [21]. We hypothesize that a reduction in Th1 signaling activity in T2DM could reduce available macrophages at the fracture site contributing to impaired fracture repair. Inflammatory cytokines TNF- $\alpha$ and IL- 6 were also predicted to be inhibited in T2DM and activated post-fracture (Figure 1). Interestingly, TNF- $\alpha$ and IL-6 are both secreted by Th1 cell subsets, which in turn activate macrophages [22]. Thus, a decrease in these inflammatory cytokines could be related to the decrease in the Th1 pathway response and a reduction of macrophage activity at the fracture site. In addition to the Th1 pathway, the granulocyte adhesion and diapedesis pathway is vital for myeloid cells such as macrophages and neutrophils to reach the fracture site and continue to promote this necessary inflammation. A reduction in this activity would result in reduced myeloid cell persistence at the fracture site, diminishing the inflammatory response [23].

Our data shows that in T2DM, inflammatory cytokines important for fracture repair are down regulated significantly (i.e. IL- $1 \beta$ and TNF, Comparing Table 1 to Table 2, z-score $>-2$ ). IL-1 $\beta$ functions during early fracture repair to recruit the necessary osteogenic cells and is consistent with IPA analysis of the post-fracture data set which shows activation of IL- $1 \beta$ (Figure 2 ). When IL1- $\beta$ deficient mice were given IL-1 $\beta$ during fracture repair, fracture repair improved when compared to controls [24]. Interestingly, other studies have shown IL-1 $\beta$ can also be a potent inhibitor of chondrogenesis and an activator of osteogenesis [25]. In this sense, our findings could indicate that suppression of IL$1 \beta$ in T2DM impairs the early inflammatory response and decreases 
McCauley J (2020) A Meta-analysis of immune signaling pathways between human type 2 diabetic tissue and mouse bone repair

Table 4. Predicted activation states of inflammatory genes in non-diabetic fracture healing

\begin{tabular}{|c|c|c|c|c|}
\hline Upstream Regulator & Molecule Type & Predicted Activation State & Activation z-score & p-value of overlap \\
\hline TGFB1 & growth factor & Activated & 5.235 & $91.94 \mathrm{E}-16$ \\
\hline FGF2 & growth factor & Activated & 2.25 & $6.93 \mathrm{E}-14$ \\
\hline BMP2 & growth factor & Activated & 3.484 & $1.71 \mathrm{E}-12$ \\
\hline CD44 & other & Activated & 2.373 & $8.23 \mathrm{E}-11$ \\
\hline TNF & cytokine & Activated & 2.908 & $2.11 \mathrm{E}-10$ \\
\hline KRAS & enzyme & Inhibited & -2.154 & $7.27 \mathrm{E}-10$ \\
\hline SPP1 & cytokine & Activated & 2.174 & $1.88 \mathrm{E}-09$ \\
\hline SMAD7 & transcription regulator & Inhibited & -2.284 & $2.67 \mathrm{E}-09$ \\
\hline RXRB & ligand-dependent nuclear receptor & Inhibited & -2.236 & $3.12 \mathrm{E}-09$ \\
\hline RUNX2 & transcription regulator & Activated & 2.391 & $5.48 \mathrm{E}-09$ \\
\hline IGF1 & growth factor & Activated & 3.239 & $1.01 \mathrm{E}-08$ \\
\hline P38 MAPK & group & Activated & 3.325 & $2.66 \mathrm{E}-08$ \\
\hline Jnk & group & Activated & 3.413 & $3.05 \mathrm{E}-08$ \\
\hline IL $1 \beta$ & cytokine & Activated & 3.311 & $3.09 \mathrm{E}-08$ \\
\hline IL1 $\alpha$ & cytokine & Activated & 4.221 & $8.15 \mathrm{E}-08$ \\
\hline
\end{tabular}

Analysis: Observation 1



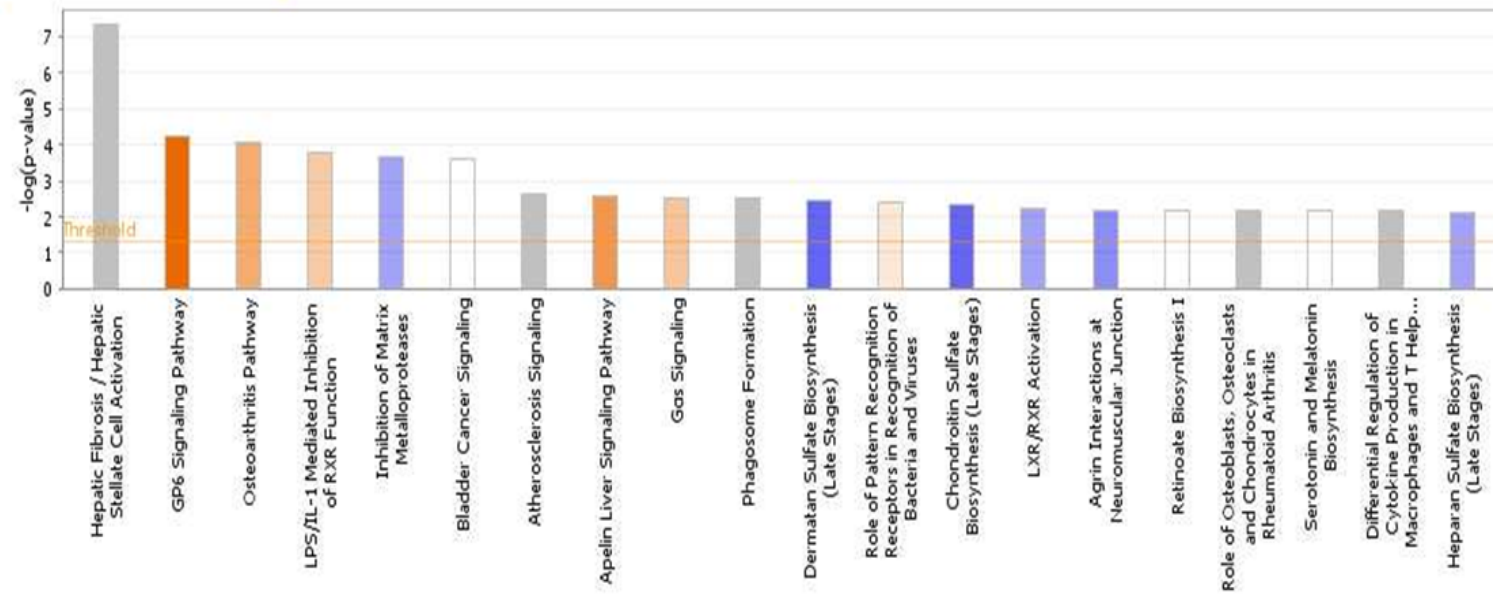

Figure 2. Canonical signaling pathways involved in early fracture repair in non-diabetic conditions

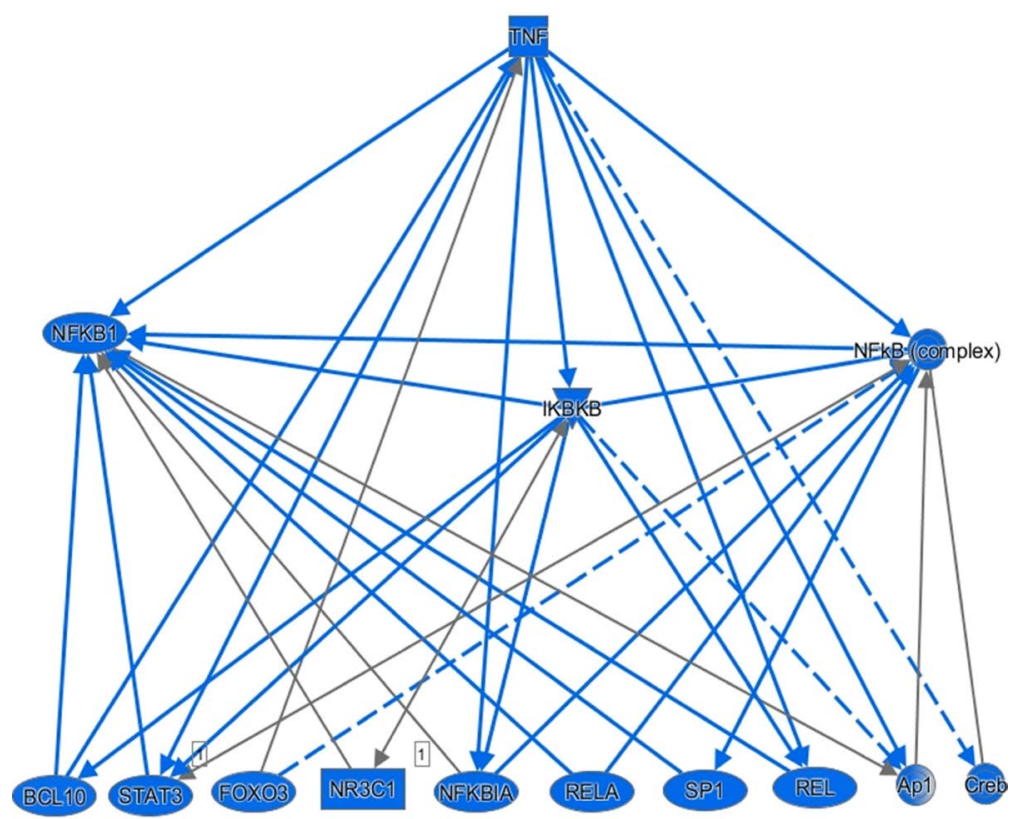

Figure 3. Predicted activity of downstream TNF- $\alpha$ signaling targets in type II diabetes 
osteoblast bone deposition. TNF- $\alpha$ also plays a significant role in fracture healing by promoting MSC recruitment and differentiation to osteoclast [22]. Data has shown that treatment with low doses of TNF- $\alpha$ can enhance the rate of callus mineralization and fracture healing in rodent fracture models [26]. Transcription factors downstream of TNF- $\alpha$ such as NF-k $\beta$ and STAT3 were also predicted to be suppressed in our signaling network (Figure 3). NF-k $\beta$ and STAT3 activation are essential for osteoclasts and osteoblasts function [27]. During early fracture repair osteoclasts assist in callus reabsorption while osteoblasts deposition mature bone. STAT3 deficient mice after fracture have impaired bone formation with reduced numbers of osteoblasts and increased osteoclasts [28]. It is hypothesized that a reduction of these mediators in T2DM could reduce the MSC number at the fracture site and negatively affect osteoprogenitor recruitment and function.

Overall, our data suggests that inflammatory pathways and molecules necessary during the early stages of fracture repair are suppressed in T2DM. Our IPA analysis provides insight into which signaling pathways and transcription targets are important when elucidating the connection between the immune system, T2DM, and bone repair.

\section{References}

1. Simmons KM, Michels AW (2015) Type 1 diabetes: A predictable disease. World $J$ diabetes 6: 380-390.

2. Kharroubi AT, Darwish HM (2015) Diabetes mellitus: The epidemic of the century. World J diabetes 6: 850-867. [Crossref]

3. Papatheodorou K, Banach M, Bekiari E, Rizzo M, Edmonds M (2018) Complications of Diabetes 2017. J Diabetes Res: 3086167.

4. Wu N, Lee Y (2013) Cost Savings Associated with the Use of Electrical Bone Growth Stimulation to Treat Diabetic Patients in the U.S. with Fracture Nonunion. J Diabetes Metab: 04. [Crossref]

5. Kanakaris N, Giannoudis PV (2007) The health economics of the treatment of longbone non-unions. Injury 38: S77-S84. [Crossref]

6. Marsell R, Einhorn TA (2011) The biology of fracture healing. Injury 42: 551-555. [Crossref]

7. Gerstenfeld LC, Cullinane DM, Barnes GL, Graves DT, Einhorn TA (2003) Fracture healing as a post-natal developmental process: Molecular, spatial, and temporal aspects of its regulation. J Cell Biochem 88: 873-884. [Crossref]

8. Wang X, Wang Y, Gou W, Lu Q, Peng J, Lu S (2013) Role of mesenchymal stem cells in bone regeneration and fracture repair: a review. Int Orthop 37: 2491-2498. [Crossref]

9. Marin C, Luyten FP, Van der Schueren B, Kerckhofs G, Vandamme K (2018) The Impact of Type 2 Diabetes on Bone Fracture Healing. Front Endocrinol 9: 6. [Crossref]

10. Hamann C, Goettsch C, Mettelsiefen J, Henkenjohann V, Rauner M, et al. (2013) Delayed bone regeneration and low bone mass in a rat model of insulin-resistant type 2 diabetes mellitus is due to impaired osteoblast function. Am J Physiol Endocrinol Metab 301: E1220- E1228. [Crossref]
11. Roy B (2013) Biomolecular basis of the role of diabetes mellitus in osteoporosis and bone fractures. World J Diabetes 4: 101-13. [Crossref]

12. Schlundt C, Khassawna TE, Serra A, Dienelt A, Schmidt-Bleek K (2018) Macrophages in bone fracture healing: Their essential role in endochondral ossification. Bone 106 : 78-89. [Crossref]

13. Martinez FO, Gordon S (2014) The M1 and M2 paradigm of macrophage activation Time for reassessment. F1000Prime Rep 6: 13. [Crossref]

14. Hoff P, Gaber T, Strehl C, Schmidt-Bleek, K, Lang, A, et al. (2016) Immunological characterization of the early human fracture hematoma. Immunol Res 64: 1195-1206. [Crossref]

15. Graves DT, Kayal RA(2008) Diabetic complications and dysregulated innate immunity Front Biosci 13: 1227-1239. [Crossref]

16. Shimoide T, Kawao N, Tamura Y, Okada K, Kaji H, et al. (2018) Role of Macrophages and Plasminogen Activator Inhibitor-1 in Delayed Bone Repair in Diabetic Female Mice. Endocrinology 159: 1875-1885. [Crossref]

17. Grover M, Gibbons SJ, Nair AA, Bernard CE, Farrugia G, et al. (2018) NIDDK Gastroparesis Clinical Research Consortium (GpCRC). Transcriptomic signatures reveal immune dysregulation in human diabetic and idiopathic gastroparesis. $B M C$ Med Genomics 11: 62. [Crossref]

18. Bais M, McLean J, Sebastiani P, Young M, Gerstenfeld LC, et al. (2009) Transcriptional analysis of fracture healing and the induction of embryonic stem cell- related genes. PloS one 4: e5393. [Crossref]

19. Baht GS, Vi L, Alman BA (2018) The Role of the Immune Cells in Fracture Healing. Curr Osteoporos Rep 16: 138-145. [Crossref]

20. Kidd P (2003) Th1/Th2 Balance: The Hypothesis, its Limitations, and Implications for Health and Disease. Altern Med Rev 8: 223-246. [Crossref]

21. McCauley J, Bitsaktsis C, Cottrell J (2020) Macrophage subtype and cytokine expression characterization during the acute inflammatory phase of mouse bone fracture repair. J Orthop Res: 1-10. [Crossref]

22. Hernandez-Pando R, Rook GA (1994) The role of TNF-alpha in T-cell-mediated inflammation depends on the Th1/Th2 cytokine balance. Immunology 82: 591-595. [Crossref]

23. Shukaliak J, Dorovini-Zis K (2000) Expression of the [beta]-chemokines RANTES and MIP-1[beta] by human brain microvessel endothelial cells in primary culture. $J$ Neuropath Exp Neur 59: 339. [Crossref]

24. Martin SJ (2016) Cell death and inflammation: the case for IL-1 family cytokines as the canonical DAMPs of the immune system. FEBS J 283: 2599-2615. [Crossref]

25. Murakami S, Lefebvre V, de Crombrugghe B (2000) Potent inhibition of the master chondrogenic factor Sox 9 gene by interleukin-1 and tumor necrosis factor-alpha. J Biol Chem 275: 3687-3692. [Crossref]

26. Glass GE, Chan JK, Freidin A, Feldmann M, Nanchahal J (2011) TNF-alpha promotes fracture repair by augmenting the recruitment and differentiation of muscle- derived stromal cells. Proc Natl Acad Sci U S A 108: 1585-1590. [Crossref]

27. Xiao E, Graves DT (2015) Diabetes and Its Effect on Bone and Fracture Healing. Curr Osteoporos Rep 13: 327-335. [Crossref]

28. Corry KA, Zhou H, Brustovetsky T, Himes ER, Li J, et al. (2019) Stat3 in osteocytes mediates osteogenic response to loading. Bone Rep 11: 100218. [Crossref]

Copyright: (C2020 McCauley J. This is an open-access article distributed under the terms of the Creative Commons Attribution License, which permits unrestricted use, distribution, and reproduction in any medium, provided the original author and source are credited. 